Case Report

\title{
Combined Spinal-Epidural Analgesia for Laboring Parturient with Arnold-Chiari Type I Malformation: A Case Report and a Review of the Literature
}

\author{
Clark K. Choi and Kalpana Tyagaraj \\ Department of Anesthesiology, Maimonides Medical Center, 4802 10th Avenue, Brooklyn, NY 11219, USA \\ Correspondence should be addressed to Kalpana Tyagaraj; kalpana_tyagaraj@msn.com
}

Received 28 January 2013; Accepted 3 March 2013

Academic Editors: R. S. Gomez, C.-H. Hsing, T. Suzuki, and E. A. Vandermeersch

Copyright (C) 2013 C. K. Choi and K. Tyagaraj. This is an open access article distributed under the Creative Commons Attribution License, which permits unrestricted use, distribution, and reproduction in any medium, provided the original work is properly cited.

\begin{abstract}
Anesthetic management of laboring parturients with Arnold-Chiari type I malformation poses a difficult challenge for the anesthesiologist. The increase in intracranial pressure during uterine contractions, coughing, valsalva maneuvers, and expulsion of the fetus can be detrimental to the mother during the process of labor and delivery. No concrete evidence has implicated high cerebral spinal fluid pressure on maternal and fetal complications. The literature on the use of neuraxial techniques for managing parturients with Arnold-Chiari is extremely scarce. While most anesthesiologists advocate epidural analgesia for management of labor pain and spinal anesthesia for cesarean section, we are the first to report the use of combined spinal-epidural analgesia for managing labor pain in a pregnant woman with Arnold-Chiari type I malformation. Also, we have reviewed the literature and presented information from case reports and case series to support the safe usage of neuraxial techniques in these patients.
\end{abstract}

\section{Introduction}

Arnold-Chiari type I malformation (ACM-I) is a congenital neurological anomaly associated with prolapse of the cerebellar tonsils into the magnum foramen $[1,2]$. Approximately $30 \%$ to $50 \%$ of the ACM-I patients have associated syringomyelia. Incidence of ACM-I ranges between $0.56 \%$ and $0.77 \%$ on magnetic resonance imaging (MRI) studies, of which $15 \%$ to $30 \%$ are asymptomatic. This abnormality is mostly predisposed to women, with a female-to-male ratio of $3: 1$. Symptoms including headaches, neck and shoulder pain, paresthesia, loss of pain and temperature sensation in the upper extremities, and unsteady gait are the usual manifestations seen during early adolescence into adulthood. Severity of the symptoms ranges from mild when tonsillar herniation is larger than $5 \mathrm{~mm}$ to severe if it is more than $12 \mathrm{~mm}$ on the sagittal MRI view [3].

A combined spinal-epidural (CSE) technique was used to provide labor analgesia for our parturient with ACMI. We also conducted a literature search for our case presentation using a public accessible medical database MEDLINE. Individual key words were entered into the query:
"Arnold-Chiari," "vaginal delivery," "pregnancy," "combined spinal-epidural analgesia," "epidural analgesia," "spinal analgesia," "cesarean section," "perioperative outcomes," and their combinations. Only articles in English language were selected. The database search yielded limited number of articles, mainly case reports and case series (Table 1).

\section{Case Presentation}

A 17-year-old female, G1P0, with history of hypothyroidism and ACM-I diagnosed during childhood, presented with symptoms of occasional headache and neck pain. She denied any visual disturbances or abnormal pain and temperature sensation in both upper extremities. She was consulted by a multidisciplinary team, including the anesthesiologist, perinatologist, and neurologist, for a planned labor induction with instrument-assisted vaginal delivery. MRI of the brain showed a $7 \mathrm{~mm}$ cerebellar tonsil herniation into the foramen magnum without syringomyelia (Figure 1).

Physical examination showed a $62 \mathrm{~kg}$ afebrile woman, in mild distress from uterine contractions, with a blood pressure 


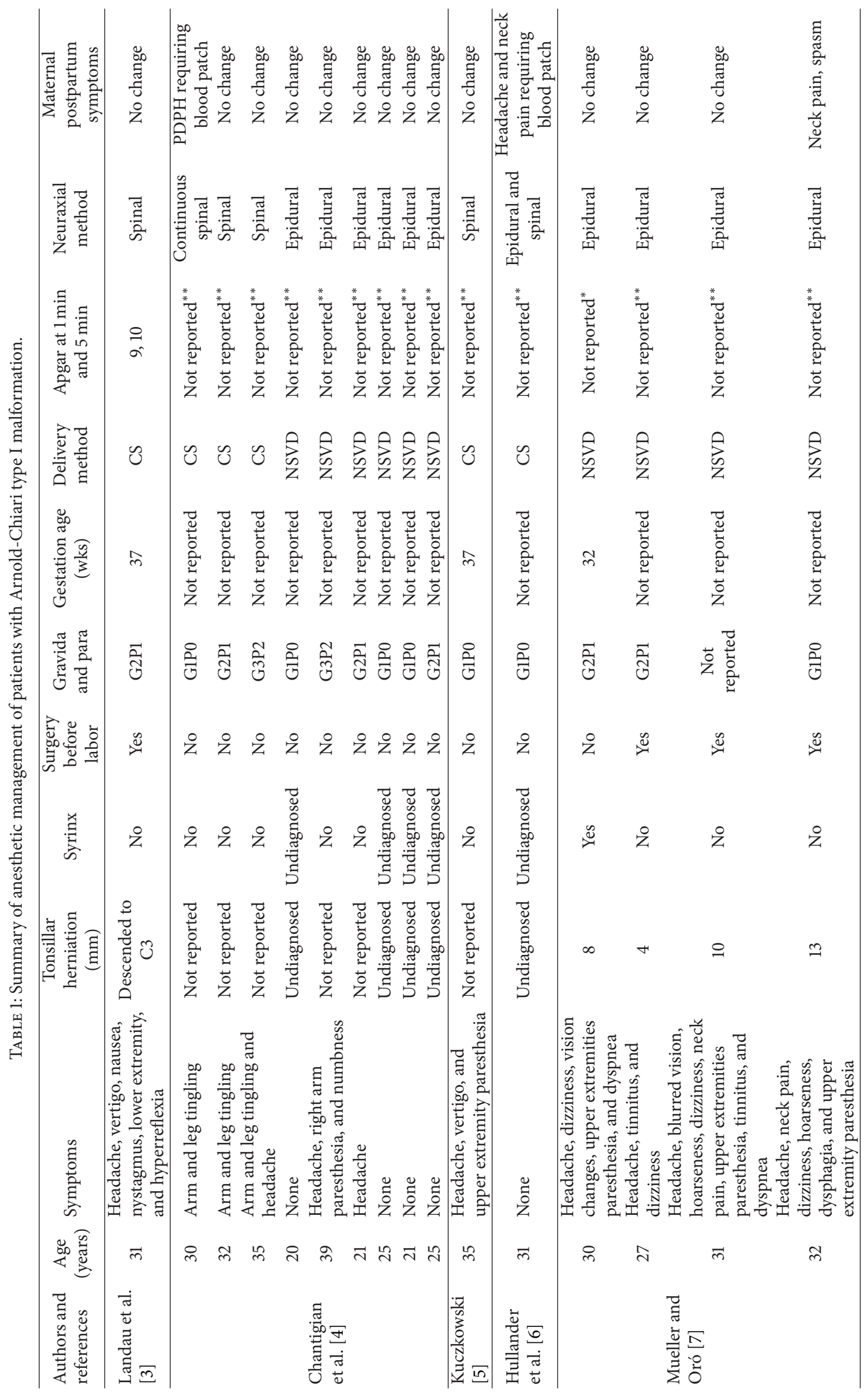




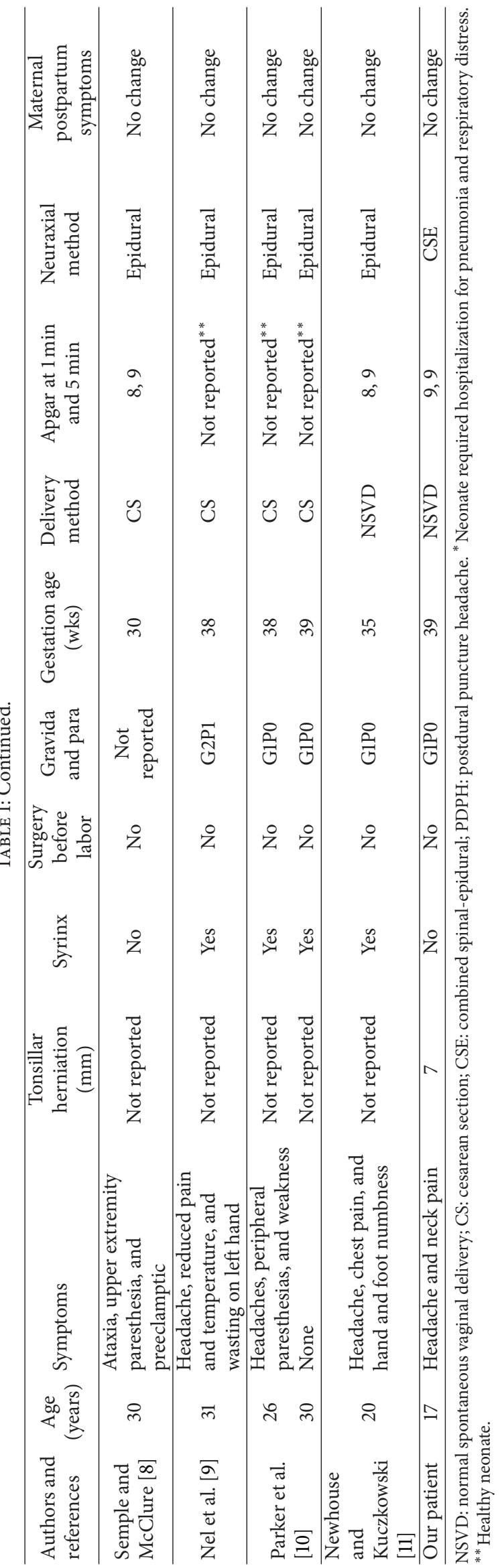




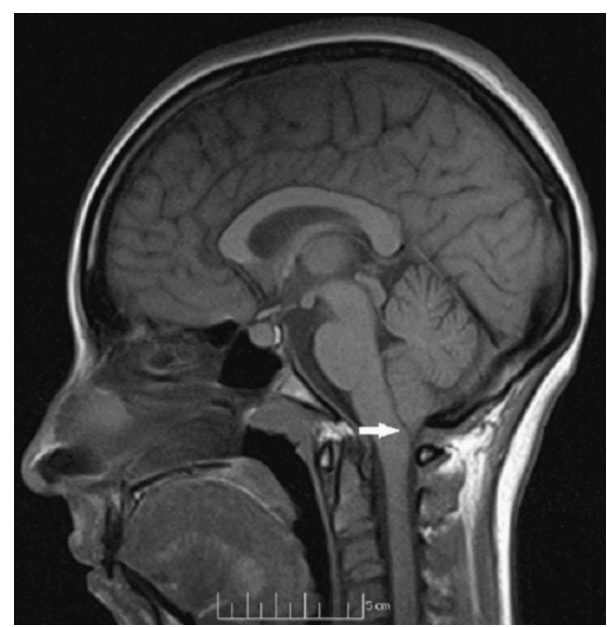

FIGURE 1: Sagittal magnetic resonance image of Arnold-Chiari type I malformation. White arrow denotes the $7 \mathrm{~mm}$ tonsillar herniation from the cerebellum. No syringomyelia is seen.

of $134 / 89 \mathrm{mmHg}$, pulse of $62 / \mathrm{min}$, respiratory rate of $12 / \mathrm{min}$, and pulse oximetry saturation of $99 \%$. Baseline laboratory values were hemoglobin $11.9 \mathrm{~g} / \mathrm{dL}$ and platelets $206 \times 10^{9} / \mathrm{L}$. With a single attempt, CSE was achieved using a 17-gauge Tuohy needle and a 5-inch 27-gauge Whitacre spinal needle at the midline of the L3-L4 interspinous space while the patient was in a sitting position. Analgesia was obtained with fentanyl $15 \mu \mathrm{g}$ and bupivacaine $1.5 \mathrm{mg}$ intrathecally. Aspiration of the epidural catheter and test dose of lidocaine 1.5\% with epinephrine $1: 200,000$ were negative. A continuous epidural infusion of bupivacaine $0.1 \%$ and fentanyl $0.0002 \%$ was initiated at the rate of $10 \mathrm{~mL} / \mathrm{h}$. A $5 \mathrm{~mL}$ bolus of bupivacaine $0.25 \%$ was injected epidurally 90 minutes before the onset of fetal expulsion and subsequently augmented with another bolus to provide a denser block to minimize the urge to push.

Fetal heart rate (FHR) and uterine contractions were continuously monitored by an external cardiotocograph. Category I FHR tracing was noted throughout the first and second stages of labor. Maternal and fetal hemodynamics were stable during the entire labor and delivery process. Labor progressed smoothly and lasted for 9 hours. The patient gave birth to a $2,995 \mathrm{~g}$ healthy girl using vacuumassisted extraction. Apgar scores at 1 and 5 minutes were 9 and 9, respectively. Estimated blood loss was $200 \mathrm{~mL}$. The patient had an uneventful postpartum course without any neurological sequelae. She was discharged home three days later.

\section{Discussion}

Attempts to demonstrate the efficacy and safety of neuraxial technique (epidural versus spinal) in a pregnant woman with ACM-I have been the subject of controversy. The risks of accidental dural puncture with the epidural needle can lead to tentorial herniation, decreased cerebral perfusion pressure, and brain shifts. Intentional intrathecal puncture using spinal needle can also present with similar manifestations but the magnitude of the effect and incidence is relatively less than the epidural needle-induced dural puncture due to the larger size of the dural puncture. Selection of smaller size epidural and spinal needles is an important factor to improve safety, but, ultimately, the danger can be significantly minimized with an experienced and trained anesthesiologist to avoid inadvertent dural puncture as well as multiple needle attempts.

The safety of providing intrathecal analgesia for immediate pain relief during labor and anesthesia for cesarean section (CS) can be effectively implemented provided that there are no acute worsening of clinical signs and symptoms of intracranial pressure (ICP). In our case presentation, we selected the use of CSE to provide immediate pain relief intrathecally for our patient and the epidural catheter to administer intermittent extradural boluses for analgesia during the course of labor and delivery as well as for anesthesia for emergent CS due to obstetrical and fetal concerns. Had our patient developed severe or new onset of neurological symptoms during pregnancy, neuraxial technique would be contraindicated. Even without any absolute contraindications, there are currently no firm guidelines to suggest preference for general anesthesia over neuraxial techniques except many believe that the patients with ACM-I have inherent high ICP; therefore, neuraxial techniques are unsuitable choice for analgesia and anesthesia [12-17]. General anesthesia is not without any risks as airway management by rapid sequence induction and intubation from direct laryngoscopy to protect parturients from aspiration can potentially increase ICP. Difficult intubation, as encountered in some of the obese pregnant patients, can cause rapid desaturation leading to hypoxia and hypercarbia which further enhance the effect on ICP. Landau et al. described a case of successful spinal anesthesia after surgical decompression of a parturient with ACM-I [3]. Moreover, spinal anesthesia for CS has been successfully performed for undiagnosed parturients with ACM-I and also those without neurosurgery [4-6].

The choice for the mode of delivery (vaginal versus CS) is also a controversial issue. The contractile force of the uterus on cerebral spinal fluid (CSF) can cause an increase in ICP and unsuspected herniation. The hydrodynamic effect on CSF pressure during labor was investigated by several researchers in the 1960s [18-21]. Changes in the intraabdominal and intrathoracic pressure secondary to sensation of pain were factors causing elevated CSF pressure during uterine contractions. Pain can induce elevated CSF but whether it contributes to a significant impact on unfavorable maternal and fetal outcomes is unclear. Mueller and Oró reported three case presentations of normal spontaneous vaginal delivery in parturients with ACM-I without receiving epidural block during labor [7]. Semple and McClure [8] and Nel et al. [9] used epidural anesthesia for CS without a clear obstetric indication other than the fear of increased ICP from straining in the second stage of delivery except from one case report described by Parker et al. [10]. Newhouse et al. managed successfully a parturient with ACM-I and sickle cell disease presented with acute pain crisis using epidural analgesia via vacuum-assisted vaginal delivery without neurological complications [11]. 
Key points in the anesthetic management of laboring parturients with ACM-I include (1) early CSE analgesia to decrease painful uterine contractions to limit intraabdominal and intrathoracic excursions to dampen elevated CSF pressure; (2) slow titration of bolus through the epidural to prevent undue extradural pressure; (3) vacuum-assisted vaginal delivery in the second stage of labor to minimize increase in ICP during fetal expulsion and maternal valsalva maneuvers; and (4) minimization of wide variations of maternal hemodynamics to preserve adequate cerebral perfusion pressure.

In summary, CSE labor analgesia can provide safe and effective pain relief to parturient with ACM-I. We emphasize the importance of multidisciplinary approach to tailor an individualized care plan for favorable maternal and fetal outcomes.

\section{Conflict of Interests}

The authors declare that they have no conflict of interests.

\section{References}

[1] G. K. Bejjani, "Definition of the adult Chiari malformation: a brief historical overview," Neurosurgical Focus, vol. 11, no. 1, pp. 1-8, 2001.

[2] G. K. Bejjani and K. P. Cockerham, "Adult Chiari malformation," Contemporary Neurosurgery, vol. 23, no. 26, pp. 1-7, 2001.

[3] R. Landau, R. Giraud, V. Delrue, and C. Kern, "Spinal anesthesia for cesarean delivery in a woman with a surgically corrected Type I Arnold Chiari malformation," Anesthesia and Analgesia, vol. 97, no. 1, pp. 253-255, 2003.

[4] R. C. Chantigian, M. A. Koehn, K. D. Ramin, and M. A. Warner, "Chiari I malformation in parturients," Journal of Clinical Anesthesia, vol. 14, no. 3, pp. 201-205, 2002.

[5] K. M. Kuczkowski, "Spinal anesthesia for Cesarean delivery in a parturient with Arnold-Chiari type I malformation," Canadian Journal of Anesthesia, vol. 51, no. 6, p. 639, 2004.

[6] R. M. Hullander, T. D. Bogard, D. Leivers, D. Moran, and D. M. Dewan, "Chiari I malformation presenting as recurrent spinal headache," Anesthesia and Analgesia, vol. 75, no. 6, pp. 10251026, 1992.

[7] D. M. Mueller and J. Oró, "Chiari I malformation with or without syringomyelia and pregnancy: case studies and review of the literature," American Journal of Perinatology, vol. 22, no. 2, pp. 67-70, 2005.

[8] D. A. Semple and J. H. McClure, "Arnold-Chiari malformation in pregnancy," Anaesthesia, vol. 51, no. 6, pp. 580-582, 1996.

[9] M. R. Nel, V. Robson, and P. N. Robinson, "Extradural anaesthesia for Caesarean section in a patient with syringomyelia and Chiari type I anomaly," British Journal of Anaesthesia, vol. 80, no. 4, pp. 512-515, 1998.

[10] J. D. Parker, J. C. Broberg, and P. G. Napolitano, "Maternal Arnold-Chiari type I malformation and syringomyelia: a labor management dilemma," American Journal of Perinatology, vol. 19, no. 8, pp. 445-449, 2002.

[11] B. J. Newhouse and K. M. Kuczkowski, "Uneventful epidural labor analgesia and vaginal delivery in a parturient with Arnold-Chiari malformation type I and sickle cell disease,"
Archives of Gynecology and Obstetrics, vol. 275, no. 4, pp. 311313, 2007.

[12] M. Agustí, R. Adàlia, C. Fernández, and C. Gomar, "Anaesthesia for caesarean section in a patient with syringomyelia and Arnold-Chiari type I malformation," International Journal of Obstetric Anesthesia, vol. 13, no. 2, pp. 114-116, 2004.

[13] L. Jayaraman, N. Sethi, and J. Sood, "Anaesthesia for caesarean section in a patient with lumbar syringomyelia," Revista Brasileira de Anestesiologia, vol. 61, no. 4, pp. 469-473, 2011.

[14] K. Murayama, K. Mamiya, K. Nozaki et al., "Cesarean section in a patient with syringomyelia," Canadian Journal of Anesthesia, vol. 48 , no. 5, pp. 474-477, 2001.

[15] R. F. Ghaly, K. D. Candido, R. Sauer, and N. N. Knezevic, "Anesthetic management during cesarean section in a woman with residual Arnold-Chiari malformation type I, cervical kyphosis, and syringomyelia," Surgical Neurology International, vol. 3, article 26, 2012.

[16] D. J. Penney and J. M. B. Smallman, "Arnold-Chiari malformation and pregnancy," International Journal of Obstetric Anesthesia, vol. 10, no. 2, pp. 139-141, 2001.

[17] G. B. Sicuranza, P. Steinberg, and R. Figueroa, "Arnold-Chiari malformation in a pregnant woman," Obstetrics and Gynecology, vol. 102, no. 5, pp. 1191-1194, 2003.

[18] A. Vasicka, H. Kretchmer, and F. Lawas, "Cerebrospinal fluid pressures during labor," American Journal of Obstetrics and Gynecology, vol. 84, pp. 206-212, 1962.

[19] E. L. Hopkins, C. H. Hendricks, and L. A. Cibils, "Cerebrospinal fluid pressure in labor," American Journal of Obstetrics and Gynecology, vol. 93, no. 7, pp. 907-916, 1965.

[20] G. F. Marx, Y. Oka, and L. R. Orkin, "Cerebrospinal fluid pressures during labor," American Journal of Obstetrics and Gynecology, vol. 84, pp. 213-219, 1962.

[21] G. F. Marx, M. T. Zemaitis, and L. R. Orkin, "Cerebrospinal fluid pressures during labor and obstetrical anesthesia," Anesthesiology, vol. 22, pp. 348-354, 1961. 


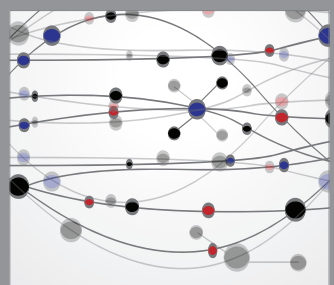

The Scientific World Journal
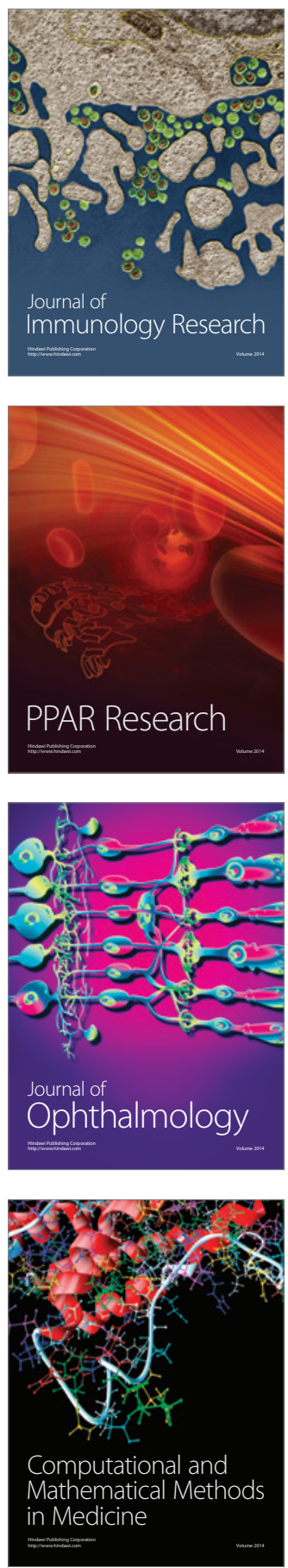

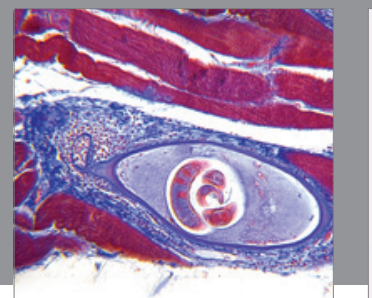

Gastroenterology

Research and Practice
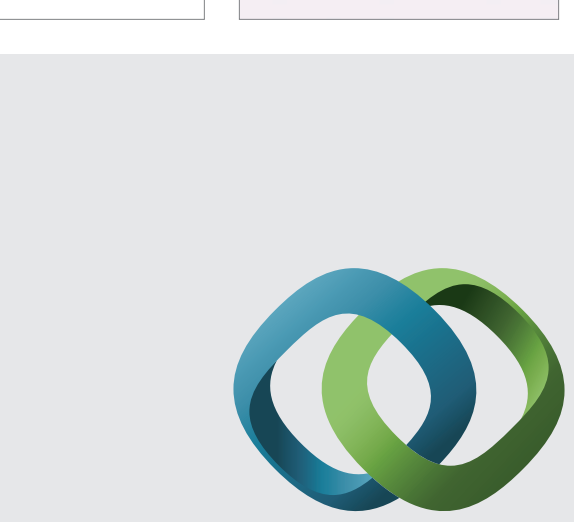

\section{Hindawi}

Submit your manuscripts at

http://www.hindawi.com
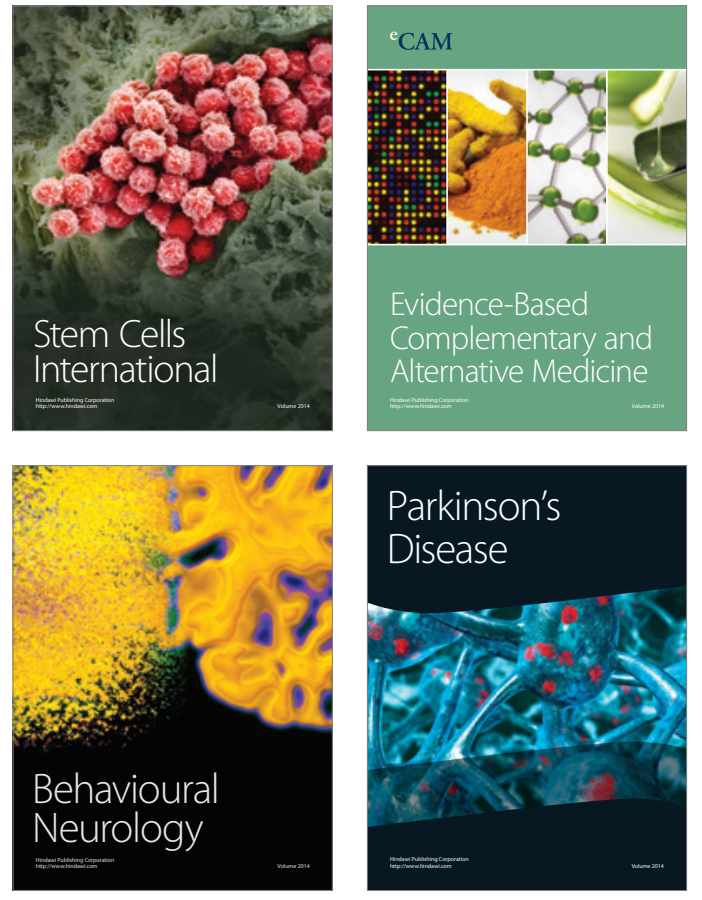
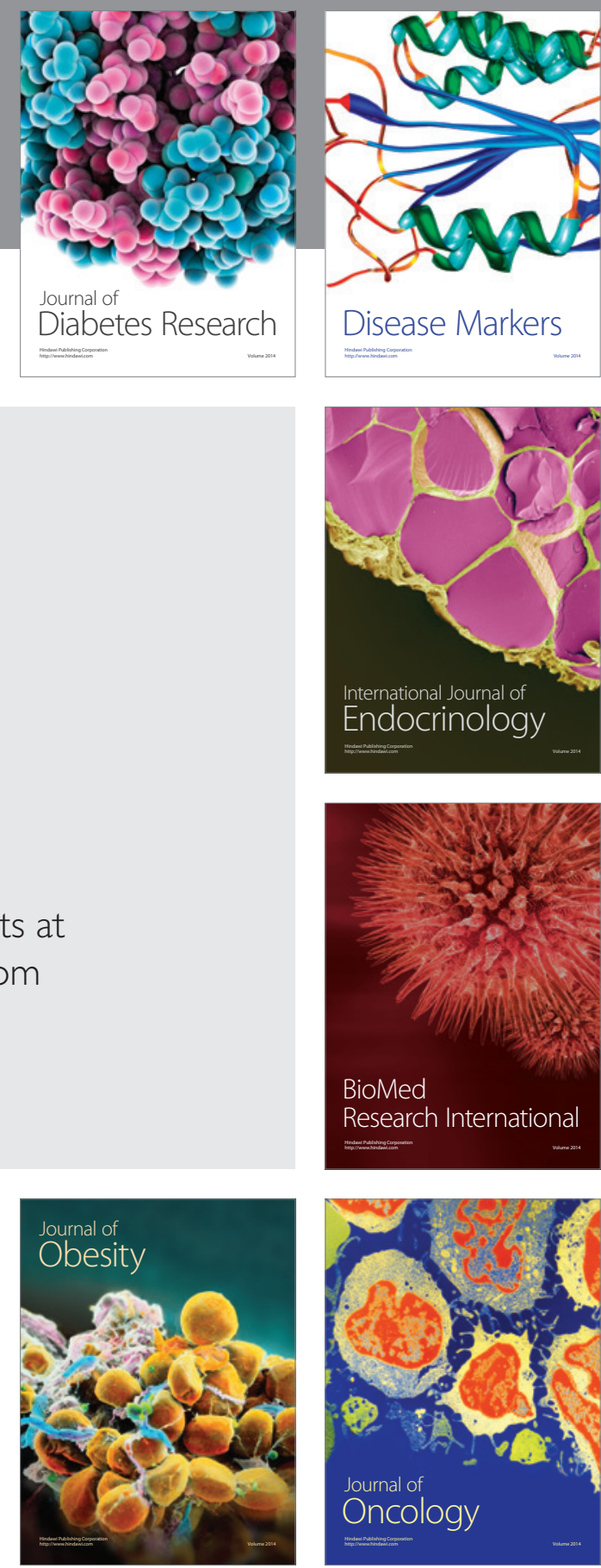

Disease Markers
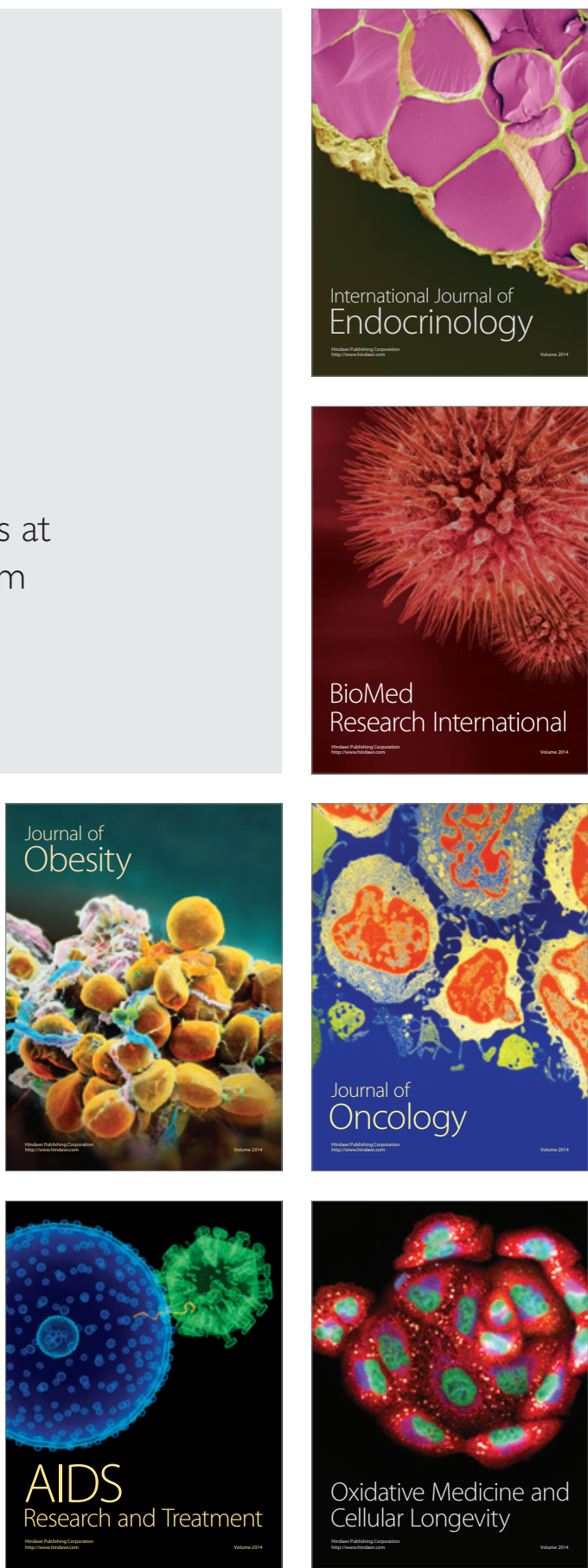